ARTIGO

\title{
Processos de liderança no Projeto de Autonomia e Flexibilidade Curricular
}

\author{
Nuno Fraga a \\ Gorete Pereira ${ }^{b}$ \\ Ana Isabel Gouveia c \\ Fernanda Gouveia d
}

\section{Resumo}

Considerando os pressupostos que, em Portugal, enquadram o Projeto de Autonomia e Flexibilidade Curricular (PAFC) elencados no Despacho $\mathrm{n}^{\mathrm{o}} 5908 / 2017$, de 5 de julho que, em "regime de experiência pedagógica, define os princípios e regras orientadores da conceção, operacionalização e avaliação do currículo dos Ensinos Básico e Secundário, de modo a alcançar o Perfil dos Alunos à Saída da Escolaridade Obrigatória" (Artigo $1^{\circ}$ ), este artigo procura desvelar na voz de cinco diretores (líderes escolares) de escolas públicas do $1^{\circ}$ Ciclo do Ensino Básico, as primeiras evidências da implementação do PAFC. Embora se trate de um processo curricular e pedagógico recente, importa compreender nessas narrativas se as escolas experienciam, de facto, tempos e espaços de uma autonomia construída e contextualizada. Neste sentido, partindo de um estudo de caso múltiplo a partir da aplicação de um inquérito por questionário, convertem-se em eixos temáticos de análise de conteúdo, as seguintes dimensões: autonomia de escola, flexibilidade curricular, prática pedagógica e avaliação. Da triangulação dos dados conclui-se que os diretores de escola assumem o PAFC como uma política educativa que abre espaço pedagógico a uma mudança de paradigma, pelo nível de autonomia outorgado às escolas, permitindo-lhes uma gestão curricular mais contextualizada, por conseguinte mais humanista, mais sensível às realidades locais e às particularidades dos seus públicos.

Palavras-chave: Autonomia de Escola. Flexibilidade Curricular. Prática Pedagógica. Pedagogia da Autonomia. Avaliação. Liderança.

\footnotetext{
a Universidade da Madeira, Funchal, Ilha da Madeira, Portugal.

b Universidade da Madeira, Funchal, Ilha da Madeira, Portugal.

c Universidade da Madeira, Funchal, Ilha da Madeira, Portugal.

d Universidade da Madeira, Funchal, Ilha da Madeira, Portugal.
} 


\section{O Projeto de Autonomia e Flexibilidade Curricular}

Em Portugal, a par das alterações estruturais e inadiáveis exigidas à escola, emergem outras preocupações respeitantes à promoção de um Ensino de qualidade e sucesso para todos, expresso em aprendizagens assumidamente "efetivas e significativas, com conhecimentos consolidados, que são mobilizados em situações concretas que potenciam o desenvolvimento de competências de nível elevado, que, por sua vez, contribuem para uma cidadania de sucesso no contexto dos desafios colocados pela sociedade contemporânea" (REPÚBLICA PORTUGUESA, 2017a).

Com efeito, e em consonância com os mecanismos da Agenda Globalmente Estruturada para a Educação (DALE, 2004), surgem apelos de organizações como a Organização para a Cooperação e Desenvolvimento Económico (OECD, 2018) ou a União Europeia (UE, 2019), à criação de condições que permitam às escolas portuguesas responder com eficácia e qualidade aos novos desafios emergentes do século XXI. Nesse enquadramento, o Despacho $n^{\circ}$ 5.908/2017 (REPÚBLICA PORTUGUESA, 2017a) regulamenta os princípios e regras de conceção, operacionalização e avaliação do currículo dos Ensinos Básico e Secundário. Esse projeto, aprovado a 5 de julho de 2017, foi aplicado enquanto experiência pedagógica nos anos letivos de 2017/2018, com garantias de acompanhamento, monitorização e avaliação.

Mas a diversidade dos contextos e a especificidade das necessidades dos alunos, implicaram a nível macro, uma abertura a novas

orientações para a concretização de uma política educativa que, assumindo a centralidade das escolas, dos seus alunos e professores, permita a gestão do currículo de forma flexível e contextualizada, reconhecendo que o exercício efetivo de autonomia em Educação só é plenamente garantido se o objeto dessa autonomia for o currículo (REPÚBLICA PORTUGUESA, 2017a).

Não obstante, por tradição, os instrumentos de autonomia das escolas não integram os processos de desenvolvimento curricular. Desse modo, é outorgado às escolas a possibilidade de participar no desenvolvimento curricular, instituindo níveis de prioridade na apropriação contextualizada do currículo e assumindo a diversidade na tomada de decisão, em consonância com o projeto educativo.

\section{Políticas educativas de gestão curricular}

A assunção do currículo como texto e práxis de significações só fará sentido se ultrapassar a mera explicação da realidade social e a dimensão discursiva 
(PACHECO, 2008), até porque os atos de ensinar e aprender exigem "a corporificação das palavras pelo exemplo" (FREIRE, 2009, p. 34). Entendido como prática de significações suportada pela política curricular que a fundamenta, o currículo só poderá ser compreendido se forem analisadas as relações que se estabelecem entre a Educação e os mecanismos de poder instituídos, daí que importa reforçar que "sem intervenção do educador, intervenção democrática, não há Educação progressista" (FREIRE, 1993, p. 52).

Do trabalho colaborativo emerge uma nova conceção de currículo que se traduz na assunção de poder pelas escolas que assumem a responsabilidade de organizar os percursos educativos dos alunos (LEITE, 2003). Depreende-se "[...] que a gestão curricular e pedagógica ocorre tendo em consideração a necessidade de estabelecer uma relação entre os alunos e o património cultural dito comum" (COSME, 2018, p. 12).

A política educativa veiculada pelo Despacho $n^{\circ}$ 5.908/2017 (REPÚBLICA PORTUGUESA, 2017a) premeia uma mudança de paradigma, que rompe com o modelo fabril de organização escolar, privilegiando mais a aprendizagem do que o ensino, nos pressupostos que nos são apresentados por Ausubel (2003), Dewey (2007) e Vygotsky (1988), e os quais são corroborados pelo Perfil do Aluno à Saída da Escolaridade Obrigatória.

É fundamental passar de um currículo prescrito para um currículo contextualizado nas experiências de vida que só se veiculam se a escola for efetivamente um centro de poder de decisão curricular, capaz de contrariar a visão enciclopedista e estéril dos currículos prescritos, procurando interpretar "a aprendizagem curricular por parte dos alunos que a ação de ensinar deve promover sistematicamente, como apropriação e uso inteligente do conhecimento, em todas as suas dimensões" (ROLDÃO, 2013, p. 134).

A flexibilização curricular constitui-se, portanto, como um imperativo democrático, social e escolar, que sugere a construção de novas respostas pedagógicas diferenciadas, exigindo "uma mudança da gramática escolar, a mudança das regras do jogo para que todos aprendam mais" (ALVES, 2017, p. 11). Mas, essa flexibilização não se refere apenas aos programas, mas também aos modos de agrupar os alunos aos espaços e tempos, aos modos de ação pedagógica, com ênfase numa vertente mais colaborativa e de trabalho em equipa. Por conseguinte, infere-se que o trabalho conjunto e o desenvolvimento de uma cultura de colaboração serão condições essenciais para o desenvolvimento desta aspiração educativa (PEREIRA, 2018). 
Se antes este "como fazer" (a última das questões clássicas acerca do currículo a ser respondida) se associava apenas "à forma de concretizar didaticamente um currículo pré-fornecido sobre o qual não havia nada a decidir" (ROLDÃO, 2017, p. 22), atualmente espera-se que os professores façam uma gestão contextualizada do currículo. Neste quadro desvela-se um dos saberes necessários à prática educativa enunciados por Freire (2009) ao referir que ensinar exige a apreensão da realidade, num quadro que caracteriza o ensino e a aprendizagem, além da lógica behaviorista do ensino transmissivo e reprodutor. "Trata-se de encontrar a melhor forma e os recursos mais eficazes para todos os alunos aprenderem, isto é, para que se produza uma apropriação efetiva dos conhecimentos, capacidades e atitudes" (REPÚBLICA PORTUGUESA, 2017b, p. 32).

As políticas educativas atuais outorgam novos poderes à escola, a ela conferindo a possibilidade de implementação de projetos e a integração das especificidades dos vários contextos locais. Com efeito, nem a escola se resume apenas a um espaço anónimo e regulado pelo poder central, nem o currículo pode ser reduzido às matérias a ensinar ou a um conjunto de atividades de ensino iguais para todos, sendo primordial perspetivar uma escola que entenda o currículo como um projeto em construção (GOUVEIA; FRAGA, 2017).

Enquanto especificidade humana, a Educação é ideológica e a assunção desta realidade responsabiliza os atores educativos e, em particular, os professores a reconfigurarem as suas práticas pedagógicas numa ação participada. Este processo que exige criticidade não pode fazer com que o professor, que se assume progressista, pense a escola como um território neutro. É-lhe exigido que "assuma a politicidade de sua prática" (FREIRE, 1993, p. 46), que se quer democrática e progressista, tal como nos é descrita por Dewey na obra Democracia e Educação (2007).

\section{Os sete tipos qualitativos de líderes educacionais}

Face à heterogeneidade discente e à crise social importada ${ }^{1}$, no sentido que the são dados por Formosinho (1992), é notório que a escola entrou numa espécie de recessão estratégica, de visão, missão e valores. Urge, nesse entendimento, desenvolver princípios inerentes à gestão das mudanças que conduzam as escolas a uma aprendizagem organizacional que as façam enquadrar o seu Projeto Educativo num ambiente que se revê instável e mutante.

${ }^{1}$ Entende-se por crise social importada o facto de a escola transpor para o seu espaço pedagógico as variáveis sociais que determinam o seu contexto de intervenção. 
O papel do líder da escola transforma-se. Deixa de ser a aplicação quase que acéfala de princípios e diretrizes oriundos de um taylorismo ${ }^{2}$ encravado nos tempos, para se assumir como um agente inspirador e proactivo, capaz de alinhar a ação da escola mediante um Projeto Educativo motivador, estimulante e promotor da mudança.

Partindo desses pressupostos, enquadramos a liderança e, em particular, os tipos qualitativos de líderes educacionais a partir do trabalho de Glanz (2003). São eles: 1. Líder Agressivo Dinâmico; 2. Líder Assertivo Dinâmico; 3. Líder Empático Dinâmico; 4. Líder Agressivo Adaptável; 5. Líder Assertivo Adaptável; 6. Líder Empático Adaptável; 7. Líder Assertivo Criativo.

São características-chave dos líderes agressivos dinâmicos o carisma e o controlo. São considerados líderes natos da sociedade, trabalhadores e visionários. A sua ação decorre da necessidade do cumprimento de objetivos que são, na generalidade, oradores hábeis, diligentes e politicamente astutos e conscientes. Outras características que os definem são, por um lado, o facto de estabelecerem metas elevadas e, por outro, a necessidade de assumirem o comando (GLANZ, 2003).

Os líderes Agressivos Dinâmicos poderão realizar melhor o seu trabalho se o foco da sua ação se centrar em dimensões educacionais fundamentais: motivar e encorajar a utilização de metodologias de ensino-aprendizagem diferenciadas; assumir possíveis erros na gestão e liderança da organização e potenciar a sua ação, a partir de uma reflexão sobre essas falhas; escutar a equipa e apoiar práticas sustentadas de gestão partilhada. Esses líderes "encarnam a liderança visionária e, sem o seu contributo, poucas coisas seriam levadas a cabo dentro de uma organização" (GLANZ, 2003, p. 34).

Por outro lado, os Assertivos Dinâmicos são inconformistas por natureza, o que os configura como agentes de mudança. Esses líderes são agentes especiais de mudança social. Entre as suas características primárias podemos encontrar o gosto por desafios, a introspeção, o pensamento independente e idealista e a honestidade.

\footnotetext{
2Entendemos o "taylorismo", a partir dos trabalhos de Taylor (2011), pela racionalidade técnica aplicada nos processos pedagógicos e que viabilizam, por exemplo, a aplicação hermética de objetivos de aprendizagem, ou a uniformidade curricular em detrimento da diferenciação pedagógica ou de processos de inclusão. Estamos perante uma abordagem que normaliza a prática pedagógica, criando padrões e standards que por natureza são excludentes. Trata-se de um modelo político-pedagógico que assume a escola como uma empresa em miniatura.
} 
Os diretores de escola com esse tipo qualitativo de líder realizam melhor a sua função se definirem um projeto educativo congruente com o contexto social, económico e cultural da escola. São pessoas essenciais no estabelecimento de objetivos curriculares e pedagógicos exequíveis e socialmente úteis. Os Assertivos Dinâmicos procuram parceiros, em que o trabalho cooperativo se insurge como metodologia de trabalho crucial. Esses líderes reconhecem que os modelos de gestão centralizadora ou descentralizadora não funcionam por si só, dado que ambas as estratégias são necessárias aos processos de gestão da mudança (GLANZ, 2003).

Os líderes do tipo Empático Dinâmico são, por natureza, carismáticos, calorosos, fiáveis, bem-humorados, articulados, emocionais, despreocupados e obstinados com grande sentido ético. Os Empáticos Dinâmicos têm como principal preocupação as pessoas e a redução dos conflitos, revelando um sentido de ética profissional muito apurado.

Os diretores de escola associados a esse tipo qualitativo de líder realizarão melhor o seu papel se estabelecerem prioridades; se reservarem tempo para si mesmos; se considerarem avocar posições de liderança de pequena ou média importância e, de acordo com Glanz (2003), se utilizarem "as suas competências interpessoais para humanizar a burocracia escolar" (p. 48). Com a sua inteligência emocional, poderão mitigar os efeitos do sistema educacional, nomeadamente a frustração e a falta de motivação dos professores.

Outro tipo qualitativo de líder é o Agressivo Adaptável orientado para o sucesso. São pessoas de recursos vastos que retiram o melhor partido das situações. São indivíduos autoconfiantes e socialmente conscientes que entendem a dinâmica dos contextos sociais. Esse tipo de líder, orientado para objetivos, opta por trabalhar nos bastidores para que os objetivos se concretizem.

No caso de diretores de escola em que sobressaia este tipo de líder, realizarão melhor o seu papel se assumirem que os fins não justificam os meios, sendo chamados a um trabalho mais cooperativo com o de grupo.

Relativamente ao tipo de líder - Assertivo Adaptável - o foco está na sua liderança prática, isto é, "não são necessariamente carismáticos, mas possuem o género de competências práticas de liderança que fazem deles bons administradores e dirigentes de escolas" (GLANZ, 2003, p. 56). Esses líderes são bons ao fazer planos, são metódicos e persistentes. Trabalham arduamente e acreditam em valores tradicionais. São pessoas diligentes, fiáveis e previsíveis. 
Embora realizem um trabalho de excelência ao nível da investigação, da construção de relatórios ou de projetos necessários à ação da escola, a intervenção destes líderes foca-se nas questões urgentes, optando por se empenharem na construção de consensos e na delegação de competências e responsabilidades, na assunção de uma liderança distribuída.

Por outro lado, os diretores do tipo de líder qualitativo - Empáticos Adaptáveis constituem a maioria dos dirigentes. Como características principais dos Empáticos Adaptáveis, destacam-se as seguintes: são paladins da ordem estabelecida, caridosos, trabalhadores de valores tradicionais e apreciadores do consenso. São indivíduos que procuram a estabilidade e acreditam na autoridade, evitando conflitos e preocupando-se com o grupo (GLANZ, 2003).

Esse tipo de líder poderá realizar melhor o seu papel de gestão e liderança ao assumir-se como modelo a seguir, encorajando a participação igualitária e reconhecendo que a escola é uma organização complexa e que lucra, por essa razão, com uma liderança partilhada e com uma ação que propicie a cada membro da organização dar o seu melhor (GLANZ, 2003).

Por último, o tipo de líder qualitativo - Assertivos Criativos - "dão mostras de uma sensibilidade apurada e de capacidades de percepção", vivendo "absorvidos pelo seu trabalho" (GLANZ, 2003, p. 68). Entre as características - chave deste líder destaca-se a sensibilidade apurada, preocupando-se com o grupo. Todavia, são imprevisíveis, complexos e de raciocínio que rompem facilmente com convenções estabelecidas. Para Glanz (2003), os Assertivos Criativos "quando integrados na organização escolar [...] têm ideias brilhantes e inovadoras sobre reformas totais ou parciais, sendo capazes de lidar com os problemas criativamente" (p. 68).

Os diretores que se identificarem com esse tipo de líder qualitativo poderão desempenhar com maior qualidade o seu papel de liderança se ajudarem os seus elementos de equipa a descobrir outras formas de construírem e desenvolverem as suas práticas, o que lhes exige maior perseverança e paciência.

\section{Metodologia}

Para a realização deste trabalho de investigação, utilizámos, como técnica de recolha de dados, a aplicação de um inquérito por questionário, com "o objectivo de examinar atitudes, opiniões, crenças ou comportamentos" (FORTIN, 2009, p. 168) dos diretores de escola que aceitaram participar, em regime de experiência 
pedagógica, do PAFC (Despacho $n^{\circ}$ 5908/2017 de 5 de julho [REPÚBLICA PORTUGUESA, 2017]).

Esse inquérito procurou, à luz dos saberes necessários à prática pedagógica, desvelar na voz dos líderes das cinco escolas públicas do $1^{\circ}$ Ciclo do Ensino Básico, onde se desenrolou o PAFC, as primeiras evidências da sua implementação. Embora se trate de um processo curricular e pedagógico recente, com a aplicação deste questionário pretendeu-se compreender se as escolas experienciam, de facto, tempos e espaços de uma autonomia construída e contextualizada, muito embora se reconheça que "a autonomia é solução para amplo espectro de problemas, mas não é uma panaceia" (GOMES, 2005, p. 294). Essas cinco escolas encontram-se distribuídas por quatro concelhos da RAM a saber: Calheta, Câmara de Lobos, Funchal e Santa Cruz. De acordo, com os Projetos Educativos de cada escola, podemos inferir que a população estudantil abrangida provém de uma mescla de classes sociais, oscilando entre a classe socioeconómica média baixa e a classe média. A população do estudo diz respeito ao total das cinco escolas públicas do $1^{\circ}$ Ciclo do Ensino Básico da Região Autónoma da Madeira que aceitaram participar em regime de experiência pedagógica no Projeto de Autonomia e Flexibilidade Curricular no ano letivo de 2017/2018 em Portugal.

O inquérito é composto por 10 questões, cuja construção resultou da análise documental da legislação em vigor (REPÚBLICA PORTUGUESA, 2017), a partir da qual emergiram os seguintes temas-chave: 1. Políticas educativas e curriculares; 2. Construção e desenvolvimento do currículo na escola; 3. Conceção, operacionalização e avaliação das aprendizagens do currículo do Ensino Básico no âmbito do PAFC; 4. Saberes necessários à prática educativa; 5. Tipos naturais de liderança.

O inquérito foi aplicado online, através da plataforma da Google Forms, salvaguardando-se a confidencialidade dos dados recolhidos, bem como o consentimento informado dos participantes. Este inquérito não foi alvo de um processo de validação, pelo facto de integrar apenas perguntas abertas, à exceção das perguntas iniciais de caracterização da população que implicavam a escolha múltipla.

A população deste estudo é composta por cinco diretores de escola (D1, D2, D3, D4, D5), sendo dois do sexo feminino e três do sexo masculino, com uma variância de idades entre 36 a 45 anos (quatro diretores) e um diretor no intervalo de 46 aos 55 anos. Relativamente às habilitações literárias, três dos respondentes são licenciados, um é mestre e outro é doutorado. A situação profissional dos cinco 
respondentes varia entre a afetação aos quadros de zona pedagógica (dois) e aos quadros de escola (três) (REPÚBLICA PORTUGUESA, 2016).

Optámos pela análise de conteúdo como técnica de análise dos dados recolhidos, que, segundo Laville e Dionne (1999) "consiste em desmontar a estrutura e os elementos desse conteúdo para esclarecer suas diferentes características e extrair sua significação" (p. 214). Para Bardin (1995), a análise de conteúdo constitui um conjunto de técnicas de análise de comunicação com o intuito de se obterem, por procedimentos metódicos e objetivos de descrição do conteúdo das mensagens, indicadores, quer sejam qualitativos, quer quantitativos, que permitam a inferência de conhecimentos respeitantes às condições de produção/ recepção dessas mensagens.

A análise baseou-se num sistema de categorização acerca da informação escrita e desenvolveu-se segundo um procedimento indutivo, sistemático e objetivo, evitando-se os riscos de enviesamento da informação. Visava à obtenção de indicadores (de natureza descritiva e quantitativa) mediante um processo de inferência, a partir do qual organizamos os dados transformados em unidades de codificação (BARDIN, 1995).

Pretendíamos captar os sentidos dos discursos analisados e realçar os significados ocultos, de acordo com uma progressão lógica, iniciando-se com a descrição, seguida de um procedimento de inferência e de subsequente interpretação (BARDIN, 1995).

A aplicação desta técnica obedeceu às três fases elencadas por Bardin (1995), nomeadamente: i) pré-análise, ii) exploração do material e iii) tratamento dos resultados, inferência e interpretação. Em primeiro lugar, num primeiro contato com o texto, realizámos uma pré-análise através duma leitura flutuante que nos proporcionou as primeiras impressões. A categorização só foi iniciada após várias leituras e baseou-se nos referenciais teóricos, assim como nos significados apreendidos do texto. Este foi sujeito a um recorte por unidades de registo, submetido a critérios de natureza semântica que corresponderam a unidades linguísticas com sentido autónomo, como frases ou expressões, que se revelaram determinantes face aos objetivos propostos.

Este trabalho exaustivo e minucioso exigiu reformulações sucessivas. A codificação utilizada foi sistematizada em grelhas de análise e resultou da combinação entre os objetivos definidos, a natureza do estudo e a nossa capacidade de inferir e interpretar, já que não existe, nem teria sentido existir uma codificação universal. 
A análise de conteúdo permitiu identificar oito categorias: Políticas educativas e curriculares; Entidades com influência nas decisões curriculares e respostas educativas; Grau de autonomia na escola; Espaços de autonomia curricular; Níveis de desenvolvimento curricular; Forças da implementação do PAFC; Fraquezas da implementação do PAFC; Princípios orientadores que sustentaram a conceção, operacionalização e avaliação do currículo na escola.

Decorrente destas categorias, apresentam-se de seguida, os resultados alcançados, cuja validação resulta de um processo de triangulação de dados (FLICK, 2009) considerando a construção simbólica significativa decorrente dos posicionamentos dos sujeitos cognoscentes no inquérito por questionário, o campo teórico de suporte e a legislação que sustentou esta investigação.

\section{Análise e interpretação dos dados recolhidos}

A leitura flutuante dos dados permitiu-nos adentrar nos tempos e espaços de autonomia construída e contextualizada e, deste modo, vislumbrar a tipologia de análise a empreender face aos objetivos de investigação delineados.

Com a interpretação dos resultados da análise de conteúdo, foram emergindo as evidências mais significativas da implementação do PFAC na voz dos líderes, enquanto política educativa que, paulatinamente, abre espaço pedagógico a uma mudança de paradigma (Quadro 1).

A análise da tabela 1. permite-nos inferir que, no domínio das Políticas Educativas e Curriculares, os diretores de escola são unânimes em concordar que os governos devem apenas formular um currículo nacional simples, baseado em objetivos/ competências e conteúdos gerais, atribuindo a cada escola a possibilidade de materializar os programas, de acordo com os seus contextos e especificidades do seu público escolar. 


\begin{tabular}{|c|c|c|c|c|c|c|c|c|c|}
\hline \multirow{5}{*}{ 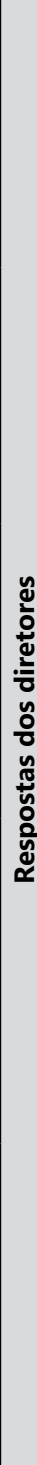 } & & 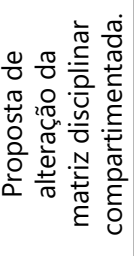 & & & & & 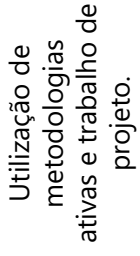 & & \\
\hline & & 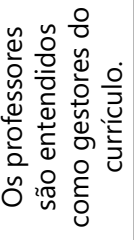 & & & & & 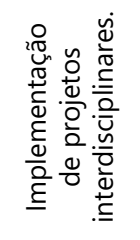 & & \\
\hline & & 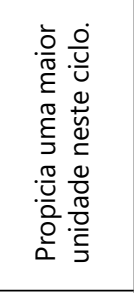 & 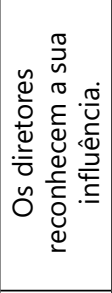 & & & & $\begin{array}{l}\dot{2} \\
\stackrel{+}{0} \\
\frac{0}{0} \\
\frac{0}{\pi} \\
\frac{0}{0} \\
0 \\
0 \\
\frac{0}{\pi} \\
\frac{0}{\pi} \\
\stackrel{0}{=}\end{array}$ & 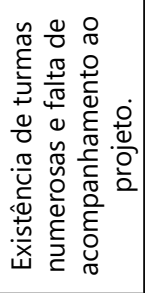 & 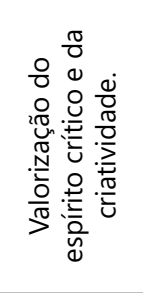 \\
\hline & & 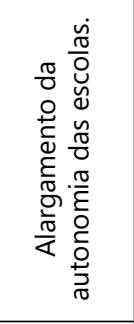 & 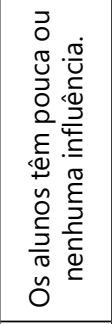 & & & & 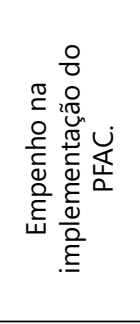 & 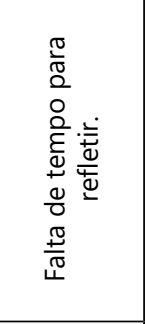 & 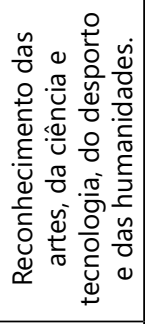 \\
\hline & & 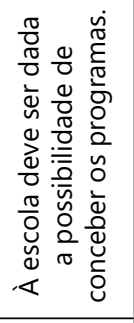 & 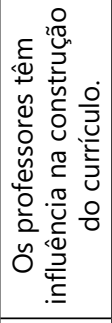 & 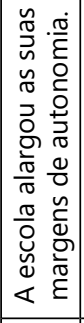 & 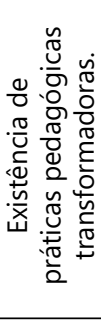 & 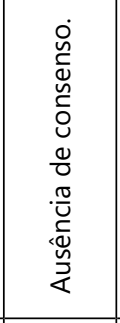 & 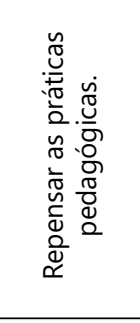 & 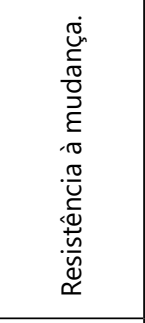 & 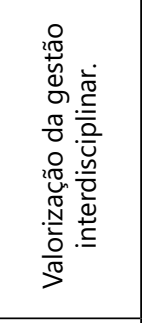 \\
\hline & & 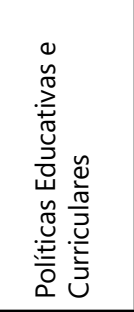 & 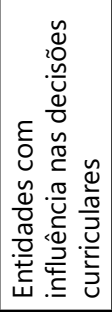 & 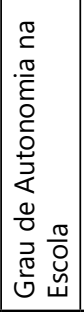 & 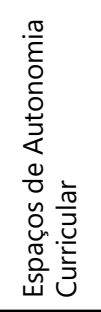 & 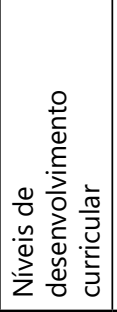 & 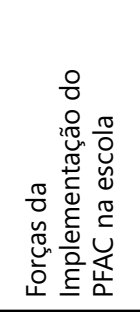 & 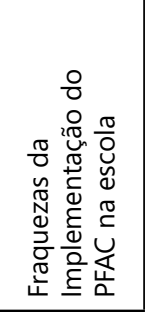 & 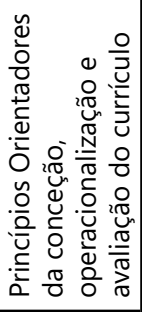 \\
\hline
\end{tabular}


Não obstante, a existência dos programas nacionais, três diretores consideram que a Escola tem margens de autonomia e de flexibilidade curricular e pedagógica, embora dois discordem dessa opinião. Todavia, com a introdução do PAFC, quatro diretores consideram que a sua escola passou a ter mais autonomia para gerir os tempos, os espaços e os recursos, sendo que dois corroboram esta ideia de forma mais vincada, destacando a reconfiguração dos espaços pedagógicos, agora "escola curricularmente inteligente" definida por Leite (2003) como "uma instituição que, em vez de se limitar a administrar e a distribuir conhecimentos na lógica de um pensamento linear e convergente, promove práticas onde se desenvolvem a criatividade e competências de ordem cognitiva, afectiva e social" (p. 10). Esta escola empoderada assume a gestão dos processos participativos de tomada de decisão, numa ação aglutinadora de todos os atores sociais que a constituem.

Na opinião de todos os inquiridos, a flexibilidade curricular propicia uma maior unidade ao $1^{\circ}$ Ciclo do Ensino Básico e permite atenuar a separação entre níveis e ciclos de escolaridade, reclamando para as escolas mais autonomia para organizar os tempos letivos da matriz curricular-base.

No que se refere à gestão do currículo, constata-se que há unanimidade na ideia de que os professores devem ser agentes diferenciadores/gestores do currículo na escola e que devem ter uma participação ativa na sua gestão, na qual todos os diretores também admitem participar, de uma forma direta ou indireta.

A flexibilização curricular pode implicar a alteração de dimensões estruturais, base do funcionamento rígido da escola, designadamente os tempos e espaços pedagógicos. Consequentemente, os respondentes sugerem a alteração da matriz disciplinar do currículo e a organização compartimentada que a suporta, implicando necessariamente uma adequada definição das aprendizagens nucleares ou do currículo nuclear e a participação dos professores na sua reinterpretação, de tal forma que não se baixe a fasquia em termos do Perfil dos Alunos. Exige que se promova as articulações necessárias para que a continuidade curricular se concretize com êxito.

No que diz respeito à influência que os diversos intervenientes poderão assumir na construção e desenvolvimento do currículo na escola, três diretores consideram que os professores têm alguma influência, enquanto dois reportam que a ação desses é preponderante. Já no que diz respeito aos alunos, três pensam que estes não assumem um papel significativo na construção e desenvolvimento do currículo e dois julgam, mesmo, que têm pouca influência. No que concerne ao papel desempenhado por cada um dos diretores, verificou-se que quatro admitem 
exercer influência nesse processo de construção e desenvolvimento do currículo na escola e apenas um mencionou ter pouca influência.

Procurando aferir o grau de autonomia de cada uma das escolas envolvidas no projeto, quatro diretores responderam que usufruem de alguma autonomia, enquanto um referiu ter muita autonomia. Estes espaços de autonomia curricular emergentes da operacionalização do PAFC foram reconhecidos pelos cinco diretores. As práticas pedagógicas perspetivadas como espaço privilegiado de ação na transformação e concretização do currículo foram valorizadas por quatro dos respondentes.

Se na dimensão intencional, o professor estrutura as competências essenciais das diferentes áreas, tendo em consideração as necessidades e possibilidades educativas dos alunos, na dimensão alusiva aos conteúdos, o professor desempenha um papel preponderante, não obstante a intervenção da administração central. Com efeito, "O domínio dos conteúdos, a sua organização, sequencialização e aprofundamento, bem como a sua abordagem com os alunos, são aspetos que fazem parte de uma autonomia do professor" (PACHECO, 2008, p. 45). Embora o seu grau de liberdade faça parte de uma autonomia subjetiva, no espaço de um currículo oculto, mesmo que eles sintam a obrigatoriedade no cumprimento do programa.

No que concerne à definição dos níveis de desenvolvimento curricular registamos a opinião de dois diretores de escola, que reconhecem competências locais de decisão, ou seja, atribuem às escolas esse papel determinante na gestão do currículo. Dois respondentes defenderam um currículo construído a nível macro, contrariando os princípios subjacentes ao projeto em análise, que reconhece às escolas a legitimidade de definição do currículo, de acordo com o seu projeto educativo e as necessidades e interesses dos seus alunos. Apenas um participante referiu a sua preferência pelo nível meso (regional), não se verificando consenso nessa matéria.

Trata-se da necessária deslocação de níveis de decisão do centro para a periferia, destacando-se o papel da liderança da escola e dos professores, procurando contrariar a lógica tradicional da organização escolar assente num modelo neotaylorista de administração. "Este é o nó que "amarra" o currículo a uma organização da escola oitocentista, mas "naturalizada" (turmas uniformes, segmentação do saber, trabalho separado de cada docente, ritmo uniforme, anualidade...), inviabilizando ou dificultando tentativas transformativas no sentido da eficácia" (ROLDÃO, 2013, p. 137). 
Embora se trate de um processo curricular e pedagógico recente, quanto à avaliação da sua implementação nas escolas em estudo, os cinco participantes apontaram alguns pontos positivos, designadamente o facto de constituir uma oportunidade para repensar a escola e as práticas pedagógicas, sendo que um dos participantes admitiu que a experiência tem sido bem sucedida, recolhendo muita aceitação por parte dos alunos e dos docentes, que revelaram um grande empenho na sua implementação e no desenvolvimento de uma organização metodológica conducente a um trabalho colaborativo, partilhando ideias entre as escolas da RAM. Tal iniciativa desencadeou ainda a implementação de projetos integrados de promoção do sucesso escolar e de diferenciação pedagógica, para além da criação de Domínios de Autonomia Curricular (DAC) na agenda semanal da turma, como a partilha de horários entre diferentes áreas disciplinares, a diversificação dos espaços pedagógicos em função da natureza das atividades a desenvolver, as quais "poderão ser realizadas nas salas (música, inglês, TIC, biblioteca) ou mesmo no ginásio ou pátio da escola" (D1).

A operacionalização de novas metodologias ativas baseadas em projetos e na resolução de problemas, a valorização das artes, do desporto, da ciência, do trabalho experimental e das tecnologias de informação e comunicação constituem outras "forças" a registar conforme podemos constatar nas palavras de um diretor (D1): "Houve a mobilização de novas metodologias/estratégias de ensino e de aprendizagem, principalmente metodologias que encorajam a curiosidade com recurso a projetos/resolução de problemas e atividades do dia a dia”.

Numa alusão às fragilidades sentidas, foram evidenciados alguns aspetos, tais como: resistência à mudança de alguns elementos, a falta de tempo no horário dos docentes para planificar, refletir e avaliar em conjunto, visto que as duas horas de serviço de escola e os horários estabelecidos para as reuniões se revelaram insuficientes. A existência de turmas com número elevado de alunos e a falta de acompanhamento na fase inicial da implementação do projeto, designadamente "na construção de alguns documentos, na elaboração de horários" (D4) foram outros constrangimentos apontados.

O inquérito por questionário apelava ainda à consideração da influência dos princípios orientadores do PAFC. Tendo por base a escala: nenhuma influência, pouca influência, alguma influência e muita influência, consideramos apenas para análise os três princípios, cujas respostas se centraram no nível mais elevado (muita influência) e os dois itens assinalados como os menos influentes. 
Os princípios reconhecidos como os mais influentes na conceção, operacionalização e avaliação das aprendizagens do currículo nas escolas que acolheram o projeto em análise, apelam à "valorização da gestão e lecionação interdisciplinar e articulada do currículo através do desenvolvimento de projetos que aglutinem aprendizagens das diferentes disciplinas, planeados, realizados e avaliados pelo conjunto dos professores" (REPÚBLICA PORTUGUESA, 2017, artigo $3^{\circ}$, alínea f). É igualmente reconhecida a assunção das artes, da ciência e tecnologia, do desporto e das humanidades como componentes estruturantes da matriz curricular das diversas ofertas educativas e formativas disponibilizadas no projeto em apreço. Por último, são valorizados o espírito crítico e interventivo, a criatividade, a curiosidade intelectual e o trabalho colaborativo e interdisciplinar no planeamento, realização e avaliação das aprendizagens.

Em oposição, foram designados pela totalidade dos respondentes os princípios com menos influência: alínea k. "Valorização da língua e da cultura portuguesas, enquanto veículos da identidade nacional", e a alínea l. "Valorização das línguas estrangeiras enquanto veículos de identidade global e multicultural e de facilitação do acesso à informação e à tecnologia".

Por fim, desafiamos os diretores de escola a refletir sobre o seu tipo natural de liderança, a partir da análise de cinquenta e seis afirmações, que nos permitiram avaliar as caraterísticas - chave do seu perfil de líder, com base no inquérito por questionário retirado da obra de Glanz (2003).

Da análise aos dados recolhidos, constatamos que os diretores de escola que participaram no estudo assumem, todos eles, o perfil de tipo de líder qualitativo de Agressivos Adaptáveis, tendo pontuado 7/8 nesse grupo. Como refere Glanz (2003) esses líderes adaptam-se "bem a situações e circunstâncias variadas", assim como perseguem "os seus objetivos agressivamente" (p. 50). Uma vez que os diretores manifestaram interesse na implementação do PAFC na sua escola, esse tipo natural de líder se perspetiva como o mais adequado, dado que, "são brilhantes e receptivos às oportunidades" (p. 54), ou como veicula Glanz (2003) "são Agressivos Adaptáveis que possuem a capacidade única de transformar as ideias em acção" (p. 54). Esta capacidade única de transformar as ideias em ação não se poderá circunscrever a uma mera curiosidade de senso comum, que nos exorta, de algum modo a arriscar fazer diferente porque a escola do século XXI assim nos impele, mas antes deve evoluir no sentido de uma curiosidade epistemológica (FREIRE, 2009) que se funde na razão crítica da prática pedagógica e dos processos de liderança distribuída. 
Das tipologias de tipo natural de líder elencadas por Glanz (2003) é, de facto, essencial que as lideranças escolares, sejam elas assumidas pelos diretores de escola ou pelos professores nos seus contextos de intervenção pedagógica, se assumam com a plasticidade necessária à adaptação e flexibilidade das suas práticas e isto

obriga a rever a missão da escola e da docência. Obriga a uma metamorfose nos modos de pensar, planear, agir e interagir." E estas mudanças não ocorrem se não ativarmos lideranças inspiradoras e transformacionais e se não criarmos as condições de gestão dos tempos e dos espaços onde trabalham alunos e professores (ALVES, 2017, p. 11).

\section{Considerações finais}

Se, por um lado, podemos constatar que os diretores de escola, de uma forma geral, reconhecem a sua influência na conceção e desenvolvimento do PAFC, por outro, registamos evidências de uma descentralização dessa gestão curricular para outros atores educativos - os professores, principais responsáveis pela ação pedagógica, assumindo o PAFC como uma política educativa que abre espaço pedagógico a uma mudança de paradigma.

Esta mudança corporifica-se no dizer de Freire (2009) pelo nível de autonomia outorgado às escolas, permitindo a elas uma gestão curricular mais contextualizada, por conseguinte mais humanista, mais sensível às realidades locais e às particularidades dos seus públicos. Neste contexto, segundo Freire (2009), o professor não é "apenas objeto da História, mas seu sujeito igualmente" (FREIRE, 2009, p. 77).

Embora este projeto apele à ampla autonomia do professor no que à dimensão pedagógica diz respeito e o facto das sugestões metodológicas apresentadas nos programas, constituírem apenas recomendações, sem caráter prescritivo, o papel do professor e da escola na gestão do currículo ainda não é reconhecido em todos os contextos escolares.

Podemos concluir que todos os processos que implicam mudanças, muitas vezes nas práticas cristalizadas da escola, se desvelam como desafios incontornáveis às lideranças educacionais. Estamos, por assim dizer, num processo de reconfiguração do projeto educativo da escola, onde a sua visão e a sua missão carecem de uma transformação progressiva e concertada com a realidade do território educativo. 
Posicionando-nos no pensamento de Freire (1993) cremos, tal como o autor, que "a melhor afirmação para definir o alcance da prática educativa em face dos limites a que se submete é a seguinte: não podendo tudo, a prática educativa pode alguma coisa" (FREIRE, 1993, p. 96).

Do posicionamento dos diretores de escola, face aos tipos naturais de liderança facultados por Glanz (2003), é percetível a existência de uma recusa ao estilo de liderança de cariz taylorista, condição essencial ao desenvolvimento do PAFC, por se tratar de um processo que evolui na razão do grau de motivação e comprometimento dos diversos atores educativos.

Não obstante a constatação das vantagens decorrentes da participação neste projeto (a importância da interdisciplinaridade, do trabalho colaborativo, da liderança partilhada e da valorização de novas competências), constata-se que a vontade de mudar não basta para que ela aconteça, na medida em que as respostas obtidas revelam a existência de dúvidas, a resistência e algumas divergências por parte de alguns professores nos modos de conceber e operacionalizar as possibilidades que este projeto oferece às escolas, deixando antever a necessidade de uma clarificação concetual e metodológica que este novo contexto requer, no âmbito da formação contínua das equipas de trabalho. 


\title{
Leadership processes in the Curricular Autonomy and Flexibility Project
}

\begin{abstract}
This article's starting point is the Curriculum Autonomy and Flexibility Project (CAFP), explained in Order No. 5,908/2017 of 5 July, which, in "pedagogical experience regime, defines the principles and rules guiding the conception, operationalization and evaluation of curriculum of basic and secondary education, in order to achieve the Profile of Students Leaving the Compulsory Schooling” (Article 1). This paper aims discovering in the opinion of five principals (school leaders) of public elementary schools, the first evidence of the implementation of CAFP. This is a recent curricular and pedagogical process, but we want to understand if schools really experience times and spaces of constructed and contextualized autonomy. In this sense, the starting point is a multiple case study. We applied a questionnaire survey, and the thematic axes of content analysis are as follows: school autonomy, curriculum flexibility, pedagogical practice and assessment. Data triangulation was performed, and it was concluded that school principals understand the CAFP as an educational policy that opens a pedagogical space to a paradigm shift, due to the level of autonomy given to schools, and that allows a more contextualized curricular management, therefore, more humanistic, more sensitive to local realities and the particularities of its publics.
\end{abstract}

Keywords: School Autonomy. Curriculum Flexibility. Pedagogical Practice. Pedagogy of Autonomy. Evaluation. Leadership.

\section{Procesos de liderazgo en el Proyecto de Autonomía y Flexibilidad Curricular}

\section{Resumen}

Considerando los presupuestos que en Portugal enmarcan el Proyecto de Autonomía y Flexibilidad Curricular (PAFC) enumerados en el Despacho $n^{\circ}$ 5.908/2017 del 5 de julio que en "régimen de práctica pedagógica, define los principios y reglas orientadoras de la concepción, operacionalización y evaluación del Currículo de la Educación Primaria y Secundaria, de modo a alcanzar el Perfil de los Alumnos Egresados de la Educación Obligatoria" (Artículo $1^{\circ}$ ) este artículo busca revelar en la voz de cinco directores (lideres escolares) de escuelas públicas del $1{ }^{\circ}$ Ciclo de Educación Primaria, las primeras evidencias de la implementación del PAFC. Aunque se trata de un proceso curricular y pedagógico reciente, es importante comprender en estas narrativas si las escuelas realmente experimentan tiempos y espacios de una autonomía construida y contextualizada. En este sentido, a partir de un estudio de caso múltiple basado en la aplicación de una indagación por cuestionario, las siguientes dimensiones se convierten en ejes temáticos de análisis de contenido: autonomía escolar, flexibilidad curricular, práctica pedagógica y evaluación. De la triangulación de los datos se concluye que los directores de escuela asumen el PAFC como una politica educativa 
que abre un espacio pedagógico para un cambio de paradigma, debido al nivel de autonomía otorgado a las escuelas, permitiéndoles una visión más contextualizada, por lo tanto más humanista, gestión curricular, más sensible a las realidades locales y las particularidades de sus públicos.

Palabras clave: Autonomía de Escuela. Flexibilidad Curricular. Práctica Pedagógica. Pedagogía de la Autonomía. Evaluación. 


\section{Referências}

ALVES, J. M. Autonomia e flexibilidade: pensar e praticar outros modos de gestão curricular e organizacional. In: PALMEIRÃO, C.; ALVES, J. M. (orgs.). Construir a autonomia e a flexibilização curricular: os desafios da escola e dos professores. Porto: Universidade Católica Editora, 2017. p. 6-14.

AUSUBEL, D. Aquisição e retenção de conhecimentos: uma perspectiva cognitiva. Lisboa: Plátano, 2003.

BARDIN, L. Análise de conteúdo. Lisboa: Edições 70, 1995.

COSME, A. Autonomia e flexibilidade curricular. propostas e estratégias de ação. Porto: Porto, 2018.

DALE, R. Globalização e educação: demonstrando a existência de uma "Cultura Educacional Mundial Comum" ou localizando uma "Agenda Globalmente Estruturada para a Educação"? Educação \& Sociedade, Campinas, v. 25, n. 87, p. 423-460, ago. 2004. https://doi.org/10.1590/S0101-73302004000200007

DEWEY, J. Democracia e educação. Lisboa: Plátano, 2007.

FLICK, U. Introdução à pesquisa qualitativa. 3. ed. São Paulo: Artmed, 2009.

FORMOSINHO, J. Organizar a escola para o (in)sucesso educativo: contributos para uma outra prática educativa. Porto: ASA, 1992.

FORTIN, M. O processo de investigação: da concepção à realização. 5. ed. Loures: Lusociência, 2009.

FREIRE, P. Política e educação. São Paulo: Cortez, 1993.

FREIRE, P. Pedagogia da autonomia: saberes necessários à prática educativa. São Paulo: Paz e Terra, 2009.

GLANZ, J. À descoberta do seu estilo de liderança: um guia para educadores e professores. Porto: ASA, 2003.

GOMES, C. A. A escola de qualidade para todos: abrindo as camadas da cebola. Ensaio: Avaliação e Políticas Públicas em Educação, Rio de Janeiro, v. 13, n. 48, p. 281-306, set. 2005. https://doi.org/10.1590/S0101-73302004000200007 
GOUVEIA, A. I.; FRAGA, N. A construção do conhecimento na educação de infância. In: CORREIA L. G.; LEÃO R.; POÇAS, S. (eds.). O tempo dos professores. Porto: Centro de Investigação e Intervenção Educativas/ Faculdade de Psicologia e de Ciências da Educação da Universidade do Porto, 2017. p. 525-539.

LAVILLE, C.; DIONNE, J. A construção do saber: manual de metodologia da pesquisa em ciências humanas. Porto Alegre: Artmed, 1999.

LEITE, C. Para uma escola curricularmente inteligente. Porto: ASA, 2003.

OECD. Curriculum flexibility and autonomy in Portugal: an OECD review. Paris, 2018. Disponível em: https://www.oecd.org/education/2030/ Curriculum-Flexibility-and-Autonomy-in-Portugal-an-OECD-Review.pdf. Acesso em: 4 maio 2020.

PACHECO, J. Organização curricular portuguesa. Porto: Porto, 2008.

PEREIRA, G. A aprendizagem colaborativa, porquê? Revista SérieEstudos - Periódico do Programa de Pós-Graduação em Educação da Universidade Católica Dom Bosco. Campo Grande, v. 23, n. 47 p. 5-25, jan./abr. 2018.

REPÚBLICA PORTUGUESA. Decreto Legislativo Regional nº 28/1016/M. Regula os concursos para seleção e recrutamento do pessoal docente dos ensinos básico e secundário e do pessoal docente especializado em educação e ensino especial da Região Autónoma da Madeira. Diário da República, Lisboa, 17 jul. 2016, n 135, Série I,

REPÚBLICA PORTUGUESA. Direção Geral da Educação. Perfil dos alunos à saída da escolaridade obrigatória. Lisboa: Ministério da Educação, 2017b. Disponível em: https://www.dge.mec.pt/sites/default/files/Curriculo/Projeto Autonomia_e_Flexibilidade/perfil_dos_alunos.pdf. Acesso em: 25 mar. 2020.

REPÚBLICA PORTUGUESA. Secretaria de Estado da Educação. Despacho n. ${ }^{\circ}$ 5908/2017. Diário da República, Lisboa, 5 jul 2017A, 2a série, n. 128. Era Despacho

ROLDÃO, M. C. Currículo e aprendizagem efetiva e significativa. Eixos da investigação curricular dos nossos dias. In: PALMEIRÃO, C.; ALVES, J. M. (orgs.) Construir a autonomia e a flexibilização curricular: os desafios da escola e dos professores. Porto: Universidade Católica Editora, 2017. p. 15-24. 
ROLDÃO, M. C. Desenvolvimento do Currículo e melhoria de processos e resultados. In: MACHADO, J.; ALVES, J. M. (orgs.). Melhorar a escola. Porto: Universidade Católica Editora, 2013. p. 131-140.

TAYLOR, F. Os princípios da gestão cientifica. Lisboa: Sílabo, 2011.

UNIÃO EUROPÉIA. Educação, formação e juventude. [S. 1.], 2019. Disponível em: https:/europa.eu/european-union/topics/education-trainingyouth_pt. Acesso em: 25 mar. 2020.

VYGOTSKY, L. S. A formação social da mente: o desenvolvimento dos processos psicológicos superiores. São Paulo: Martins Fontes, 1988.

\section{Informações sobre os autores}

Nuno Fraga: Doutor em Educação, Professor Auxiliar na Universidade da Madeira. Diretor do Centro de Investigação em Educação da mesma universidade. Contato: nfraga@staff.uma.pt

(iD) http://orcid.org/0000-0002-3382-6357

Gorete Pereira: Doutora em Ciências da Educação - Inovação Pedagógica. Professora Auxiliar na Universidade da Madeira. Investigadora Integrada no Centro de Investigação em Educação da mesma universidade. Contato: goretepereira@staff.uma.pt

iD http://orcid.org/0000-0002-1804-8104

Ana Isabel Gouveia: Doutora em Currículo e Inovação Pedagógica. Professora Auxiliar Convidada na Universidade da Madeira. Contato: ana.gouveia@staff.uma.pt

iD http://orcid.org/0000-0002-8488-5453

Fernanda Gouveia: Doutora em Ciências da Educação. Professora Auxiliar Convidada na Universidade da Madeira. Investigadora Integrada no Centro de Investigação em Educação da mesma universiade. Contato: mfgouveia@staff.uma.pt

(iD) http://orcid.org/0000-0001-8354-5046 